\title{
CARACTERIZAÇÃO DO AÇO SAE-4140 TEMPERADO EM ÁGUA, SALMOURA E ÓLEO E, POSTERIORMENTE, REVENIDO*
}

\author{
Torben Ulisses da Silva Carvalho ${ }^{1}$ \\ Leonardo Vilarinho Antunes Junior ${ }^{1}$ \\ Renan Correa Aranha ${ }^{1}$ \\ Antônio Charles Cavalcante Barbosa ${ }^{1}$ \\ Yann Vidal Perez ${ }^{1}$ \\ Lucas de Freitas Brasil Marins ${ }^{1}$ \\ Carlos Vinicius Paes Santos ${ }^{2}$
}

\section{Resumo}

A têmpera é um dos tratamentos térmicos mais utilizados nos aços, visando o aumento de sua dureza a partir de mudanças drásticas em sua microestrutura. A fim de aliviar as tensões provindas desse tratamento, realiza-se o revenido, fazendo com que o aço obtenha propriedades mecânicas viáveis ao uso. Este trabalho teve como objetivo realizar os tratamentos térmicos de têmpera em água, salmoura e óleo e, posteriormente, o revenido no aço SAE-4140 fornecido pela SINOBRAS, uma siderúrgica de Marabá-PA. Foi realizada a caracterização microscópica das amostras antes e depois dos tratamentos, sendo possível visualizar as mudanças na microestrutura do material, além da confirmação do aumento de resistência mecânica através do ensaio de dureza.

Palavras-chave: Tratamento Térmico; Têmpera; Revenido; SAE-4140.

\section{DESCRIPTION OF THE SAE-4140 STEEL WATER, BRINE AND OIL QUENCHED AND, AFTER, TEMPERING}

\section{Abstract}

Quenching is a heat treatment most used in steels, aiming to increase its hardness from drastic changes in its microstructure. In order to relieve the stresses coming from that treatment is carried out tempering, making the steel obtain viable mechanical properties for use. This work was aimed at making the thermal quenching in water, oil and brine and then tempering the SAE-4140 steel provided by SINOBRAS, a steel company from Marabá-PA. Microscopic characterization of the samples before and after treatment was conducted, and can view the changes in microstructure of the material, besides confirming the increase of strength through the hardness test.

Keywords: Heat Treatment; Quenching; Tempering; SAE-4140.

1 Graduando em Engenharia de Materiais, Estudante, Faculdade de Engenharia de Materiais, Universidade Federal do Sul e Sudeste do Pará, Marabá, Pará, Brasil.

2 Graduado em Engenharia de Materiais, Bacharel, Faculdade de Engenharia de Materiais, Universidade Federal do Sul e Sudeste do Pará, Marabá, Pará, Brasil. 


\section{INTRODUÇÃO}

O aço SAE 4140 é utilizado em aplicações que requeiram uma combinação de dureza moderada e uma boa resistência e tenacidade, mas em que as condições de serviço sejam moderadamente severas. O aço 4140 está disponível como barra, vergalhão, peças forjadas, chapas, placas, tiras e peças fundidas. Ele é usado para muitas peças de máquinas de alta resistência (algumas delas nitretadas), tais como bielas, virabrequins, juntas de direção, eixos, peças de bombas, tubulação de alta pressão, grandes engrenagens industriais, flanges, peças de máquinas-ferramenta, chaves e pregos [1].

O termo geralmente aceito para tratamento térmico de metais e ligas metálicas é "aquecimento e arrefecimento de um metal ou liga de metal sólida de tal forma, que capacita obter as condições e/ou propriedades específicas." Aquecimento para o único propósito de trabalho a quente (como em operações de forjamento) é excluído desta definição [2].

A normalização consiste no aquecimento do aço a uma temperatura acima da zona crítica, seguido de resfriamento ao ar tranquilo. Esse tratamento térmico visa refinar a granulação grosseira, sendo usada como um tratamento preliminar à têmpera e ao revenido, justamente para produzir estrutura mais uniforme, além de reduzir a tendência ao empenamento [3]. A têmpera consiste no aquecimento do aço até sua temperatura de austenitização seguido de resfriamento rápido. O constituinte final desejado é a martensita, aumentando a dureza e resistência à tração [4]. A ductilidade e a tenacidade da martensita podem ser aprimoradas e as tensões internas podem ser aliviadas por um tratamento térmico denominado revenido. Esse tratamento consiste no aquecimento até uma temperatura abaixo da eutetóide (250 a $650^{\circ} \mathrm{C}$ ) por um período de tempo específico [5].

Tomando o aço SAE-4140 como material de estudo, foram realizados os tratamentos térmicos de têmpera e revenido, buscando uma avaliação das mudanças das propriedades mecânicas, além da mudança microestrutural visualizada através da análise micrográfica da peça atacada quimicamente.

\section{MATERIAIS E MÉTODOS}

Para a realização dos tratamentos térmicos, foi utilizado o aço SAE-4140. Os equipamentos utilizados estão listados a seguir: forno Jung para têmpera, forno Linn para revenido e forno mufla para normalização (Figura 1); Termopar e Durômetro de bancada. Para a análise metalográfica foram utilizados: Jogos de lixas d'água com malha crescente $\left(n^{\circ} 80,100,120,220,320,400,600,800,1000\right.$ e 1200); Lixadeira e politriz; Pasta de diamante de $6 \mu \mathrm{m}, 3 \mu \mathrm{m}$ e $1 \mu \mathrm{m}$; Nital $2 \%\left(2 \mathrm{~mL}\right.$ de $\mathrm{HNO}_{3}$ em $98 \mathrm{~mL}$ etanol) e Microscópio Óptico de Reflexão Olympus BX51. 

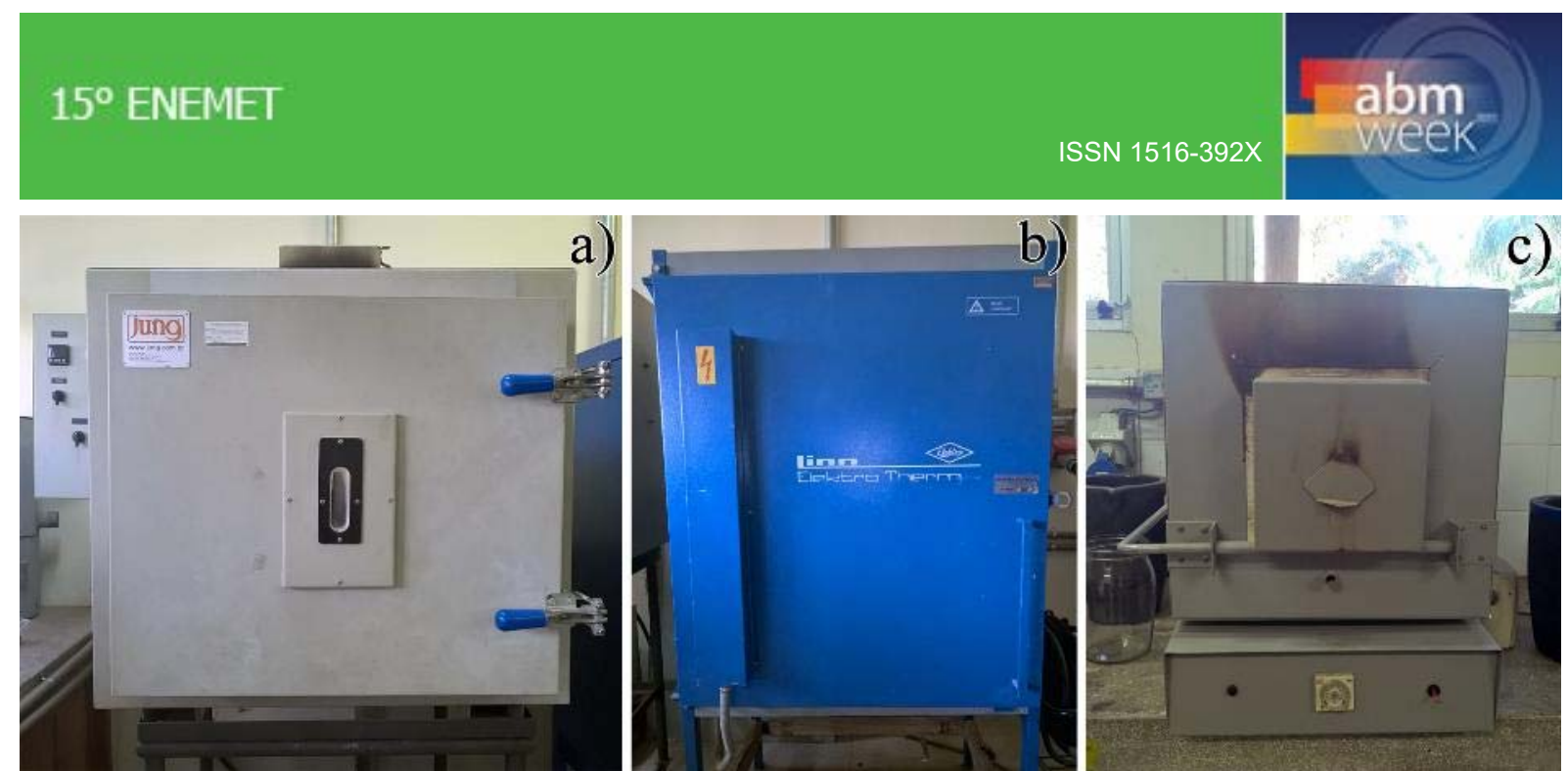

Figura 1. Fornos Jung utilizado para têmpera (a), Forno Linn utilizado para revenido (b) e Forno mufla utilizado para normalização (c).

A empresa SINOBRAS, forneceu uma análise química do aço para melhor especificação do material. Foi realizada a normalização do aço SAE-4140 no forno mufla, na temperatura de patamar de $870^{\circ} \mathrm{C}$ por uma hora, seguido de resfriamento ao ar. Após realizado esse tratamento, foi feita a análise de dureza da peça. Para a têmpera, a peça foi dividida em três partes, sendo estas postas no forno Jung, na temperatura de patamar de $855^{\circ} \mathrm{C}$, durante uma hora, seguido de resfriamento brusco em três meios de resfriamento em cada parte da peça: água, óleo e salmoura. As amostras passaram pelo revenido no forno Lynn a uma temperatura de patamar de $200^{\circ} \mathrm{C}$, apenas para aliviar as tensões residuais provindas da têmpera. Antes e após os tratamentos térmicos, foi realizado o ensaio de dureza com um durômetro de bancada da marca Pantec nas peças em dez pontos diferentes, a fim de obter uma média (Figura 2). Todos os tratamentos térmicos foram realizados no Laboratório de Solidificação da Faculdade de Engenharia de Materiais.

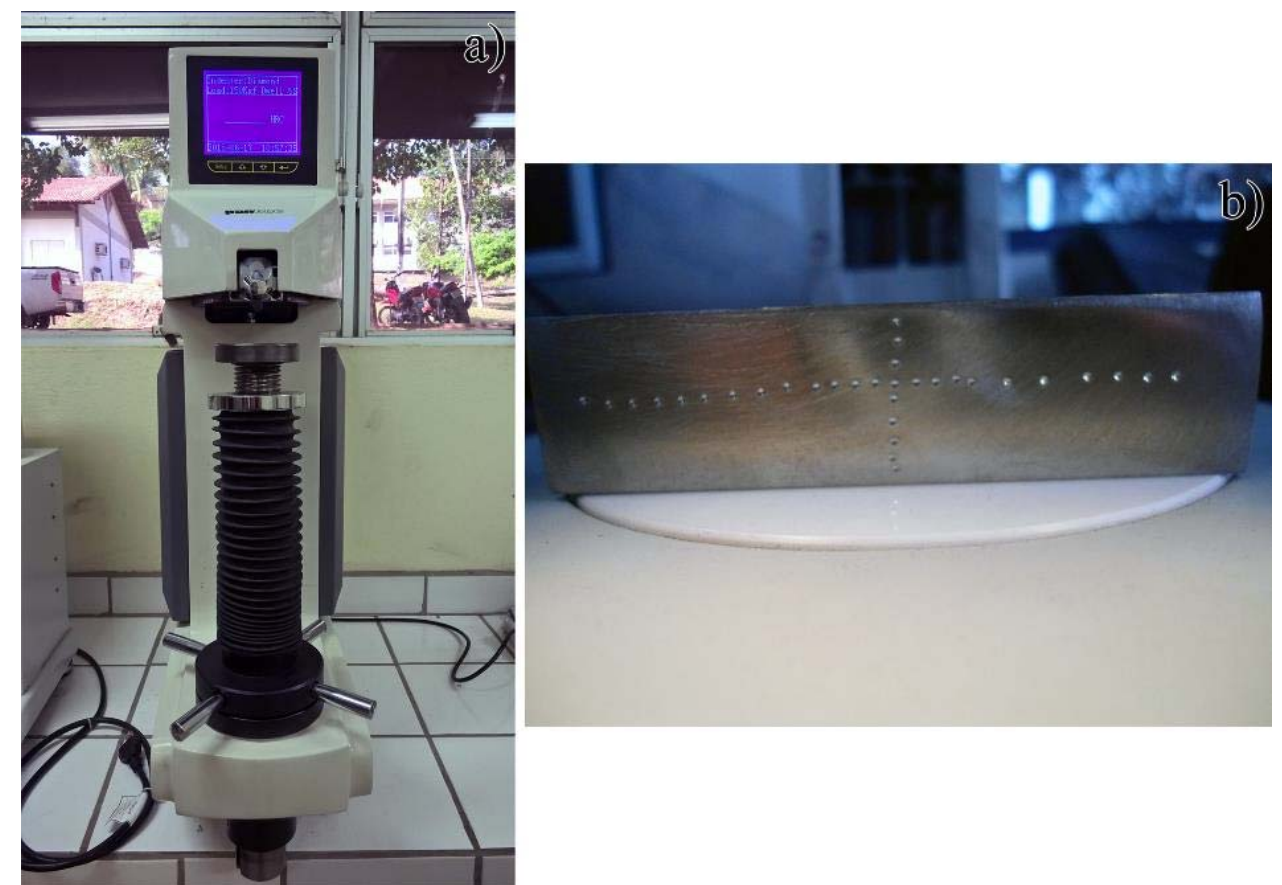

Figura 2. Durômetro (a) e peça normalizada ensaiada (b).

As amostras que sofreram os tratamentos térmicos foram caracterizadas a fim de visualizar suas microestruturas constituintes. Primeiramente, as peças foram lixadas 
numa sequência de lixas d'água com malha crescente $\left(n^{\circ} 80,100,120,220,320\right.$, $400,600,800,1000$ e 1200) e polidas com pasta de diamante de $6 \mu \mathrm{m}, 3 \mu \mathrm{m}$ e $1 \mu \mathrm{m}$, seguindo para o ataque químico com Nital $2 \%$ no Laboratório de Preparação de Amostras. As análises microscópicas foram realizadas no Laboratório de Microscopia Ótica da Faculdade de Engenharia de Materiais utilizando o Microscópio Óptico de Reflexão Olympus BX51, visualizado na Figura 3.

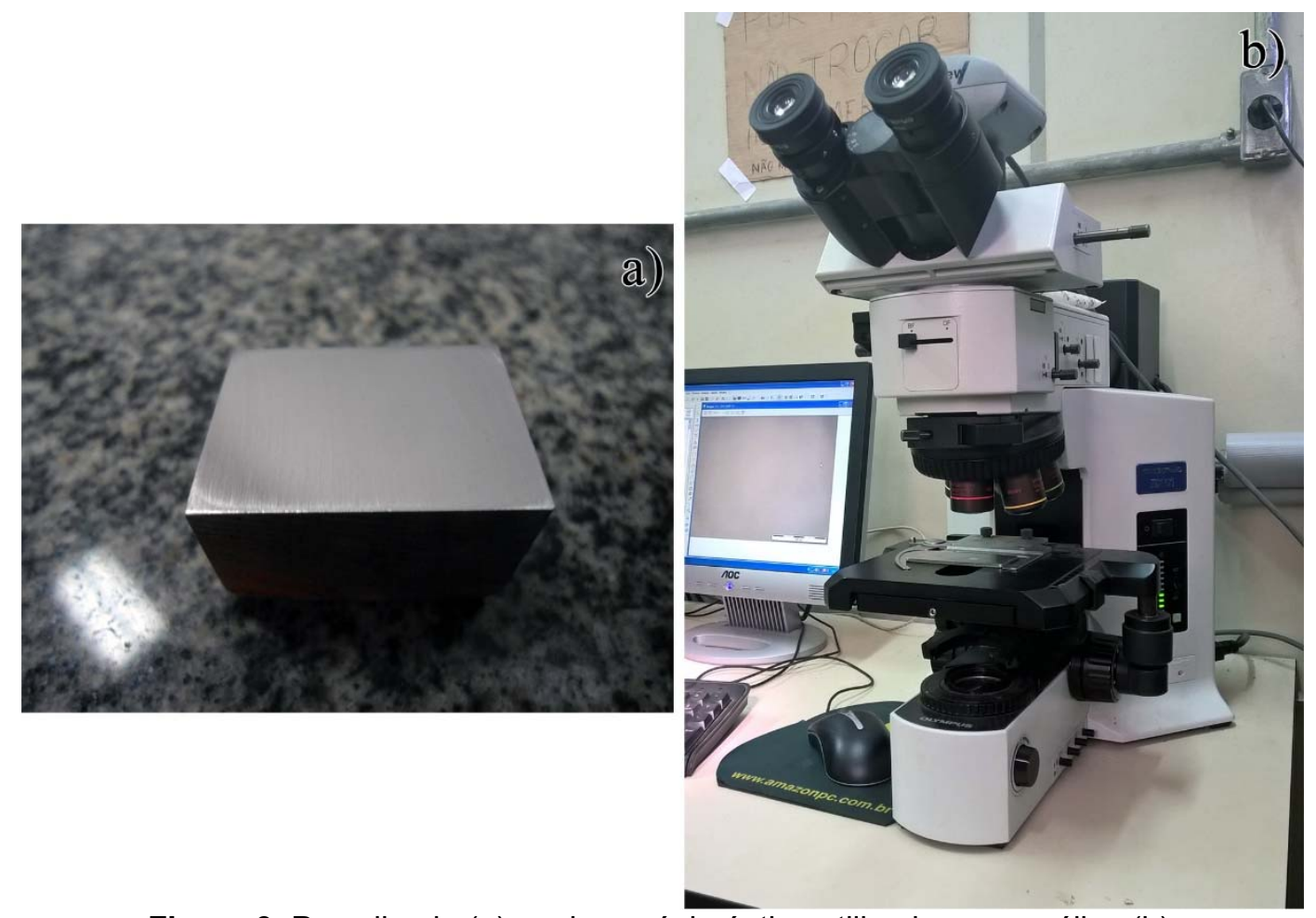

Figura 3. Peça lixada (a) e microscópio óptico utilizado para análise (b).

\section{RESULTADOS E DISCUSSÃO}

Foi feita a análise química do aço na empresa Sinobras com o equipamento de análise de modelo Thermo ARL 3460 Analyzer Metals. A Tabela 1 exibe a composição química do aço SAE-4140.

Tabela 1. Composição química do aço SAE-4140 utilizado

\begin{tabular}{ccccccc}
\hline $\mathbf{C}$ & $\mathbf{M n}$ & $\mathbf{P}$ & $\mathbf{S}$ & $\mathbf{S i}$ & $\mathbf{C r}$ & $\mathbf{M o}$ \\
\hline $0,385 \%$ & $0,823 \%$ & $0,032 \%$ & $0,019 \%$ & $0,256 \%$ & $0,936 \%$ & $0,170 \%$ \\
\hline
\end{tabular}

É visto que a porcentagem de carbono e de elementos de liga estão corretas com o proposto para os aços cromo-molibdênio utilizados para a fabricação de elementos estruturais.

As amostras do aço SAE-4140 normalizadas apresentaram uma média de dureza igual a 25,74 HRC. Dureza semelhante à descrita por Gerdau [6], que diz que este aço deve estar entre 23 e $38 \mathrm{HRC}$ quando normalizado.

A microestrutura visualizada na Figura 4, exibe a microestrutura característica de um aço hipoeutetóide, possuindo perlita (parte mais clara) em matriz ferrítica (parte mais escura). 

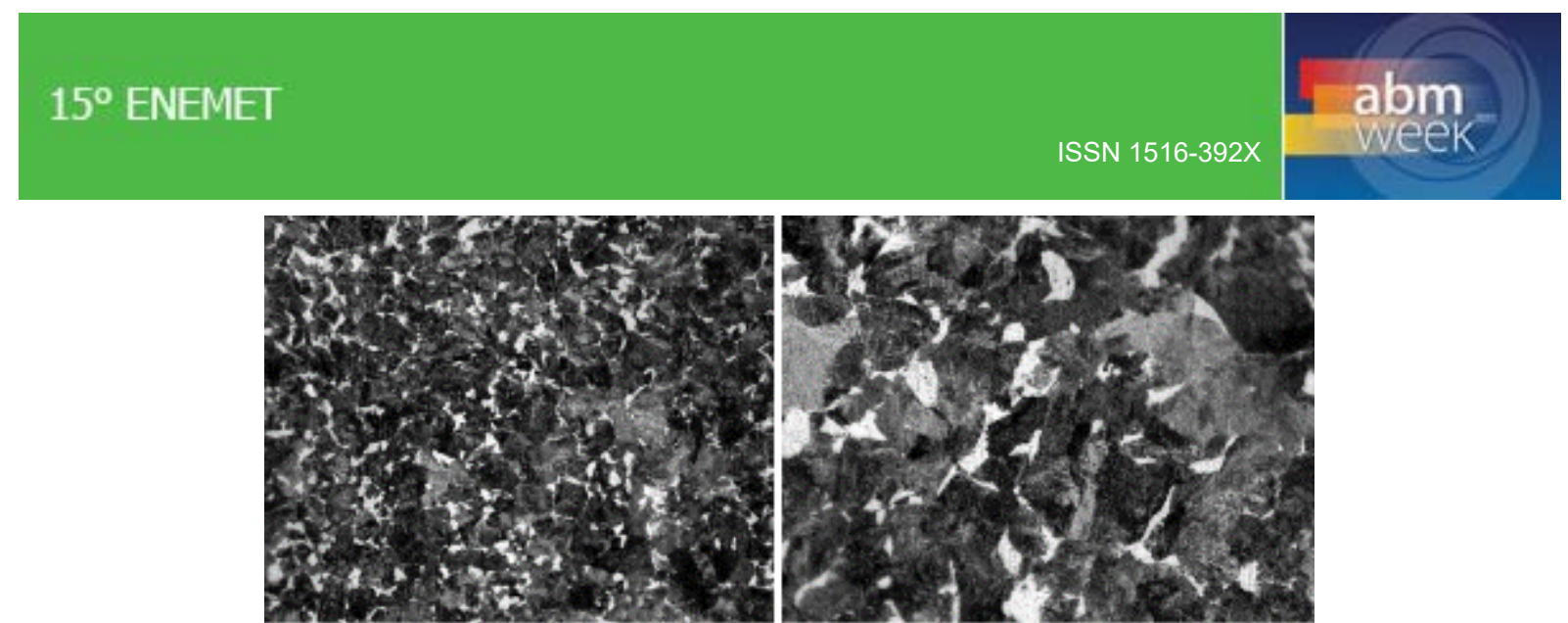

a)

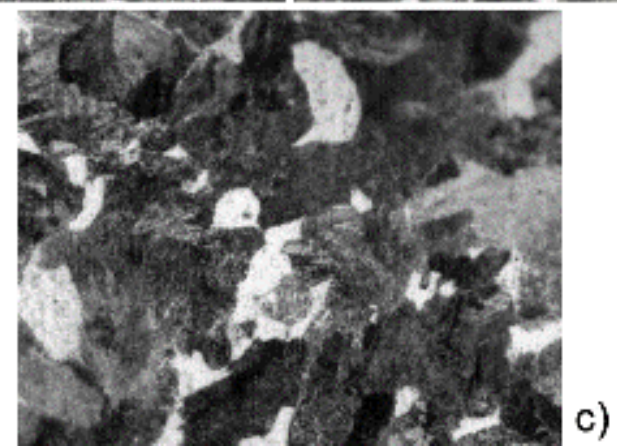

b)

c)

Figura 4. Microestrutura do aço SAE-4140 normalizado. Aumento de 300x (a), 750x (b) e 1500x (c).

Realizada a têmpera, foi obtida uma elevação de dureza para os três tipos de resfriamento. Na salmoura, foi alcançada a maior dureza com um valor de 56,50 HRC; seguido disso, utilizando a água como meio de resfriamento, a dureza alcançou uma média de 56,10 HRC, variando pouco da salmoura. O menor aumento de dureza conseguido foi no meio de resfriamento a óleo, com um valor médio de 53,04 HRC.

A microestrutura presente visualizada após a têmpera constitui-se majoritariamente de martensita nos três meios de resfriamento, a responsável pelo aumento de dureza. A Figura 5 exibe esse microconstituinte.
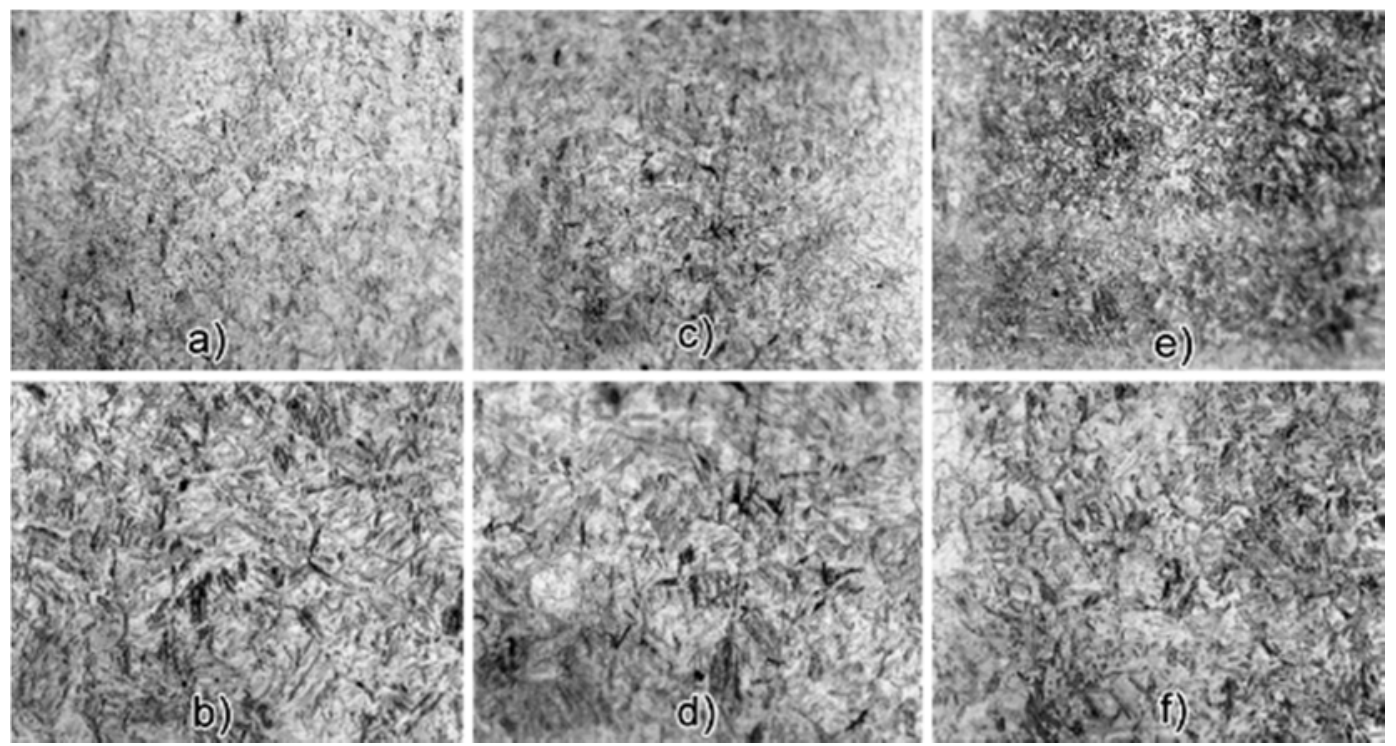

Figura 5. Micrografia do aço SAE-4140 temperado em água com aumento de $750 x$ (a) e 1500x (b); temperado em óleo com aumento de $750 x$ (c) e 1500x (d); temperado em salmoura com aumento de $750 x(e)$ e $1500 x(f)$.

A salmoura, como já esperado, foi o meio de resfriamento com a maior severidade de têmpera, alcançando a maior dureza dentre os outros meios. 
A fim de aliviar as tensões residuais do processo de têmpera, foi realizado o revenido. Com isso, as durezas das amostras diminuíram, porém não tão significativamente. A média de dureza para as amostras resfriadas em salmoura foi igual a $53,78 \mathrm{HRC}$; já o material resfriado em água ficou com dureza no valor de $53,21 \mathrm{HRC}$ quando revenido. As peças temperadas em óleo obtiveram dureza de 52,1 HRC após sofrer o revenido.

A microestrutura visualizada na Figura 6 mostra uma certa homogeneização adquirida pelo revenido, o que deve ter sido o motivo da diminuição da dureza nas peças.
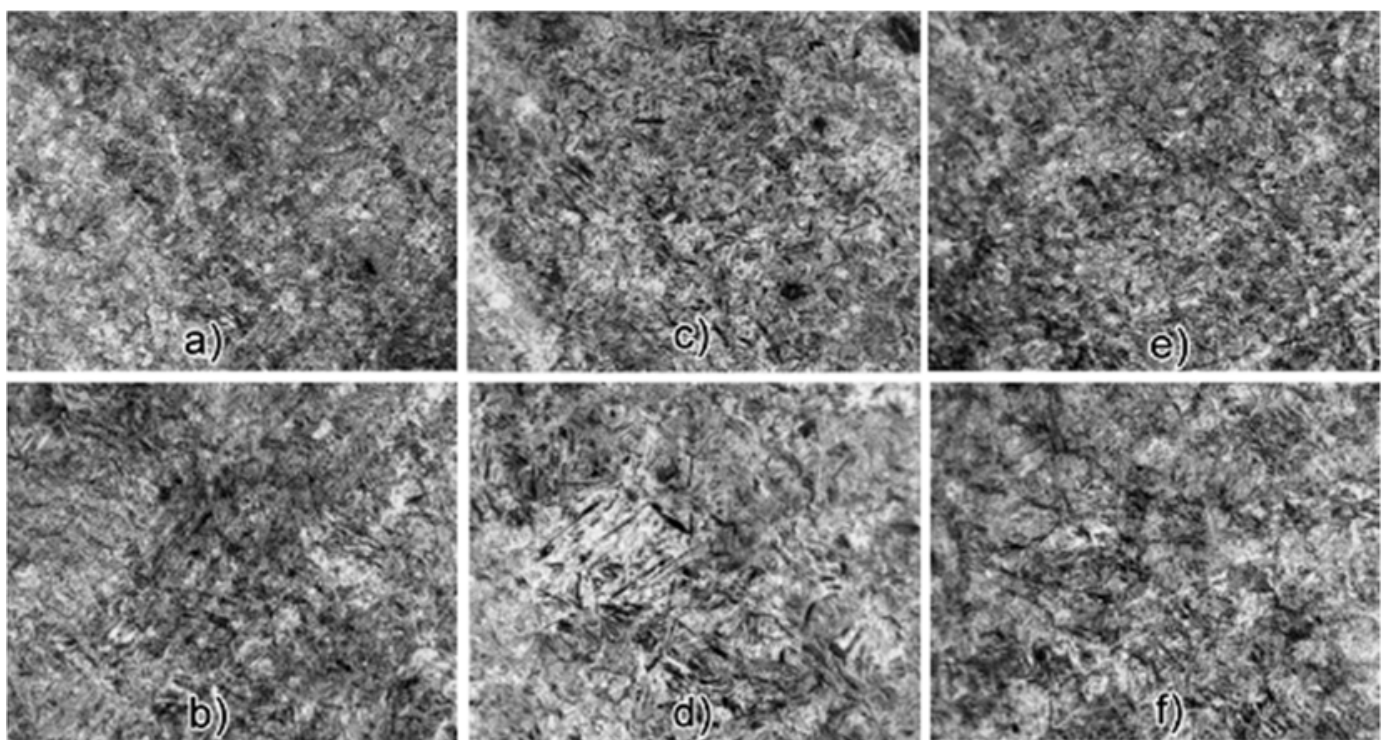

Figura 6. Micrografia do aço SAE-4140 temperado em água e revenido com aumento de $750 x$ (a) e 1500x (b); temperado em óleo e revenido com aumento de 750x (c) e 1500x (d); temperado em salmoura e revenido com aumento de $750 x$ (e) e $1500 x$ (f).

A Figura 7 exibe, de forma geral, as faixas de dureza obtidas em cada tratamento térmico relacionado, possibilitando uma melhor visualização dos dados obtidos, notando a pequena variação entre os meios de resfriamento.

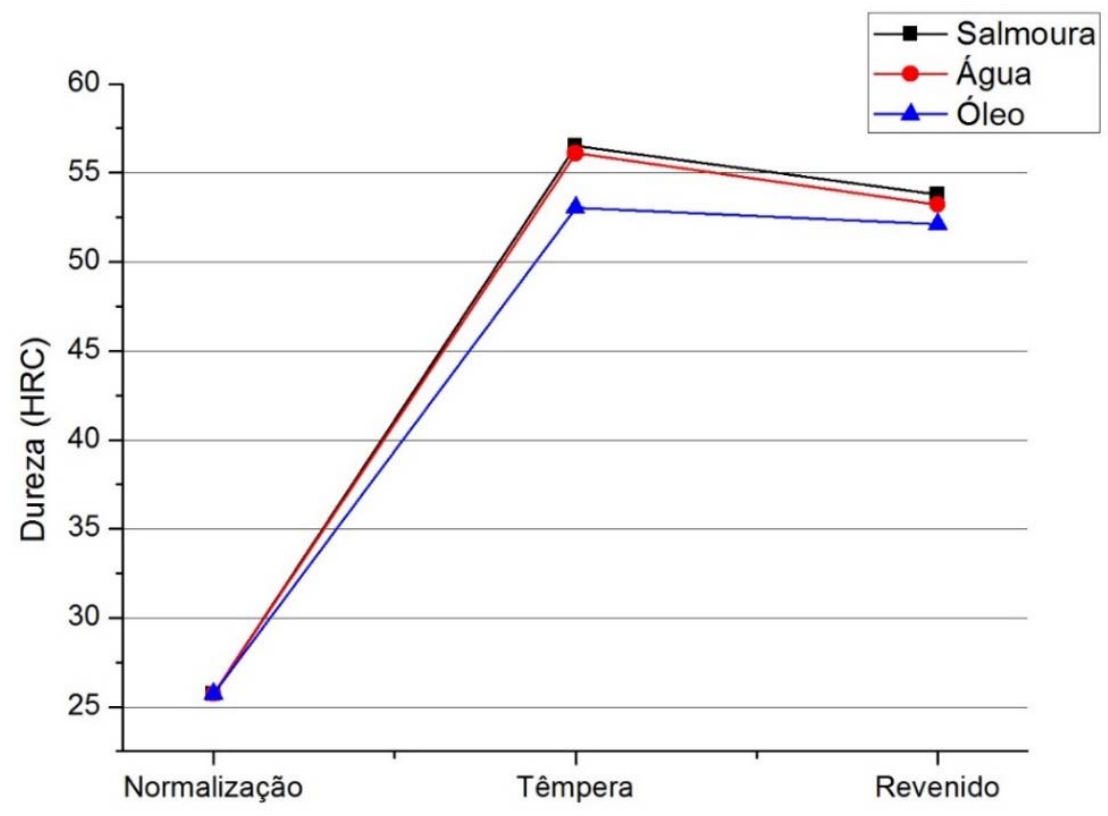

Tipo de Tratamento 


\section{CONCLUSÃO}

Figura 7. Faixas de dureza das peças tratadas termicamente.

A partir da microestrutura apresentada e dos dados de dureza colhidos, foi visto que os tratamentos térmicos de normalização, têmpera e revenido tiveram sucesso no aço SAE-4140. Observou-se que as faixas de dureza foram correspondentes para cada tratamento realizado.

A normalização apresentou microestrutura semelhante à literatura, além da dureza também. No caso da têmpera, a severidade do meio não foi tão bem visualizada, mostrando pouca variação de dureza entre as peças resfriadas em água e as peças resfriadas em salmoura. $O$ revenido poderia ter sido a um patamar de temperatura maior, buscando até uma dureza secundária pela faixa dos $600^{\circ} \mathrm{C}$, porém o tratamento foi viável na diminuição das tensões residuais, além de homogeneizar sutilmente a microestrutura do aço.

Os tratamentos térmicos são de grande importância na engenharia, ocupando um valor de responsabilidade enorme quando se aborda a necessidade de otimizar as propriedades mecânicas do material para as solicitações que lhe forem concebidas no projeto.

\section{REFERÊNCIAS}

1 American Society for Metals. ASM Handbook: Properties and Selection: Irons, Steels, and High-Performance Alloys. Ohio: ASM International, 1993.

2 Dosset JL, Boyer HE. Practical Heat Treating: Second Edition: ASM International, 2006.

3 Chiaverini V. Aços e ferros fundidos. São Paulo: ABM, 2012.

4 Lima AS. Construção e aferição de um dispositivo para a realização de ensaios de temperabilidade [trabalho de conclusão de curso]. Marabá: Faculdade de Engenharia de Materiais, Universidade Federal do Pará; 2012.

5 Callister WD. Ciência e engenharia de materiais: uma introdução. São Paulo: LTC, 2008.

6 Gerdau. Manual de Aços. São Paulo: Gerdau, 2003. 